\title{
Traumatic thoracic aortic rupture: Caught between a thoracic vertebral osteophyte and a hard place
}

\author{
Patrick O. Myers, MD, ${ }^{\mathrm{a}}$ Anne-Lise Hachulla-Lemaire, $\mathrm{MD},{ }^{\mathrm{b}}$ and Nicolas Murith, $\mathrm{MD}^{\mathrm{a}}$
}

\footnotetext{
From the a Division of Cardiovascular Surgery, and the ${ }^{\mathrm{b}}$ Department of Radiology, Geneva University Hospitals and Faculty of Medicine, Geneva, Switzerland.

Disclosures: Authors have nothing to disclose with regard to commercial support.

Received for publication Aug 3, 2015; accepted for publication Aug 8,2015; available ahead of print Sept 1, 2015.

Address for reprints: Patrick O. Myers, MD, Division of Cardiovascular Surgery, Geneva University Hospitals \& School of Medicine, 4 Rue Gabrielle-Perret-Gentil, 1211 Geneva, Switzerland (E-mail: patrick.myers@hcuge.ch).

J Thorac Cardiovasc Surg 2015;150:1661-2

$0022-5223 / \$ 36.00$

Copyright (c) 2015 by The American Association for Thoracic Surgery

http://dx.doi.org/10.1016/j.jtcvs.2015.08.012
}

A 54-year-old construction site worker was admitted after being injured by a 70-kg metal door falling from a crane. He was in hemodynamically stable condition. Physical examination revealed multiple face contusions, an open right ankle fracture, and abdominal tenderness with guarding. Bedside ultrasonography showed perisplenic and pelvic dense fluid. Computed tomography showed a contained rupture of the distal thoracic descending aorta at the level of the diaphragm (Figure 1), with a large hematoma in the posterior mediastinum extending and compressing the left atrium and active leak of contrast from the posterior aspect of the aorta. There was no pericardial effusion. A prominent anterior osteophyte of the 11th and 12th thoracic vertebrae was noted just at the level of the aortic rupture. Other lesions included LeFort 2 facial and multiple cervical fractures, hepatic and splenic lacerations, and right adrenal, acetabular, and distal tibial shaft fractures.

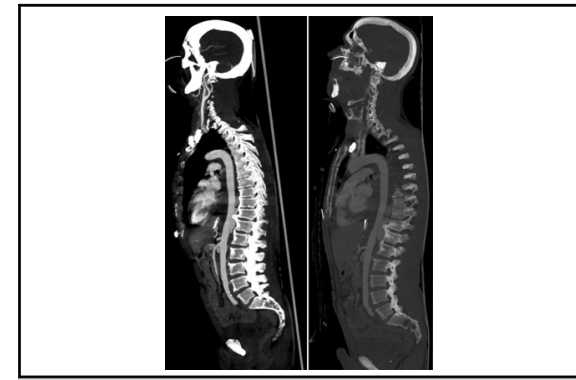

Posterior thoracic aortic rupture in direct relationship with an anterior osteophyte.

Central Message
This imaging illustrates thoracic aortic rupture
between a thoracic vertebral osteophyte and a
heavy weight.

See Editorial Commentary page 1663.

The patient required rapid transfusion for unstable hemodynamic condition with a decreasing hemoglobin. A Medtronic Valiant (Medtronic plc, Minneapolis, Minn) stent graft was placed in the descending thoracic aorta, covering the pseudoaneurysm and extending just proximally to the celiac trunk.

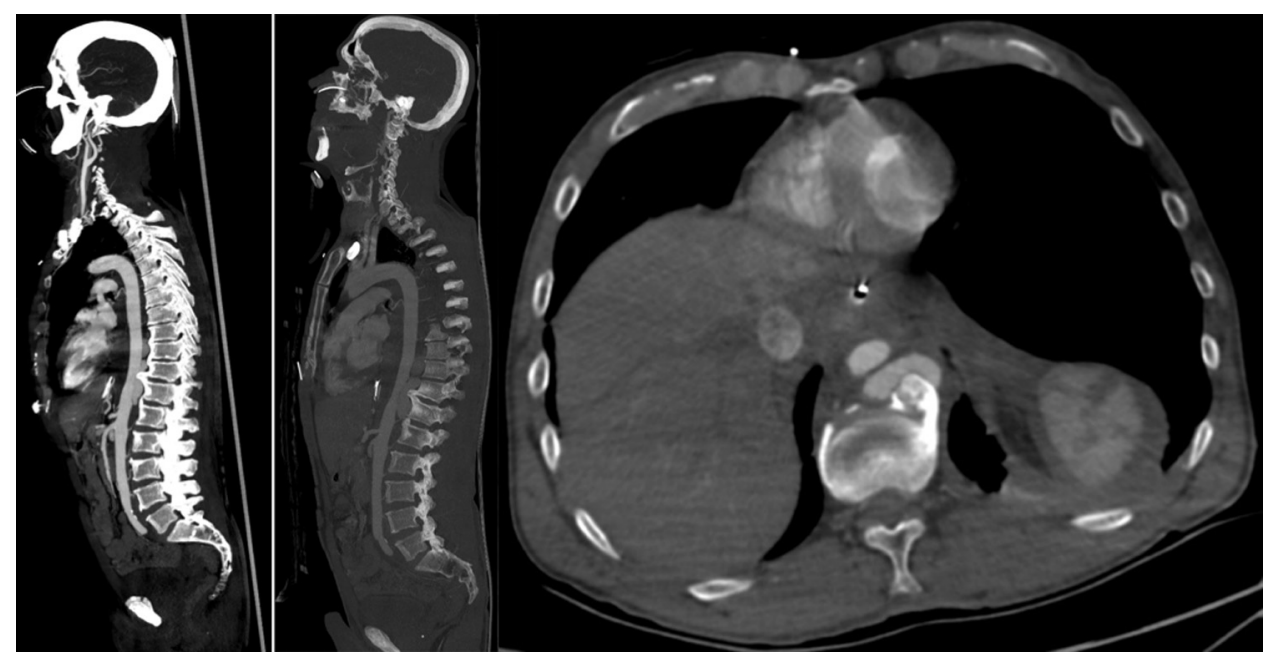

FIGURE 1. Preoperative computed tomographic angiography. The descending thoracic aorta shows posterior rupture in direct relationship with an anterior osteophyte of the 11th and 12th thoracic vertebrae. The axial image (far right) shows posterior extravasation of contrast product from the aorta, in direct relationship with the osteophyte, with a posterior mediastinal hematoma. 


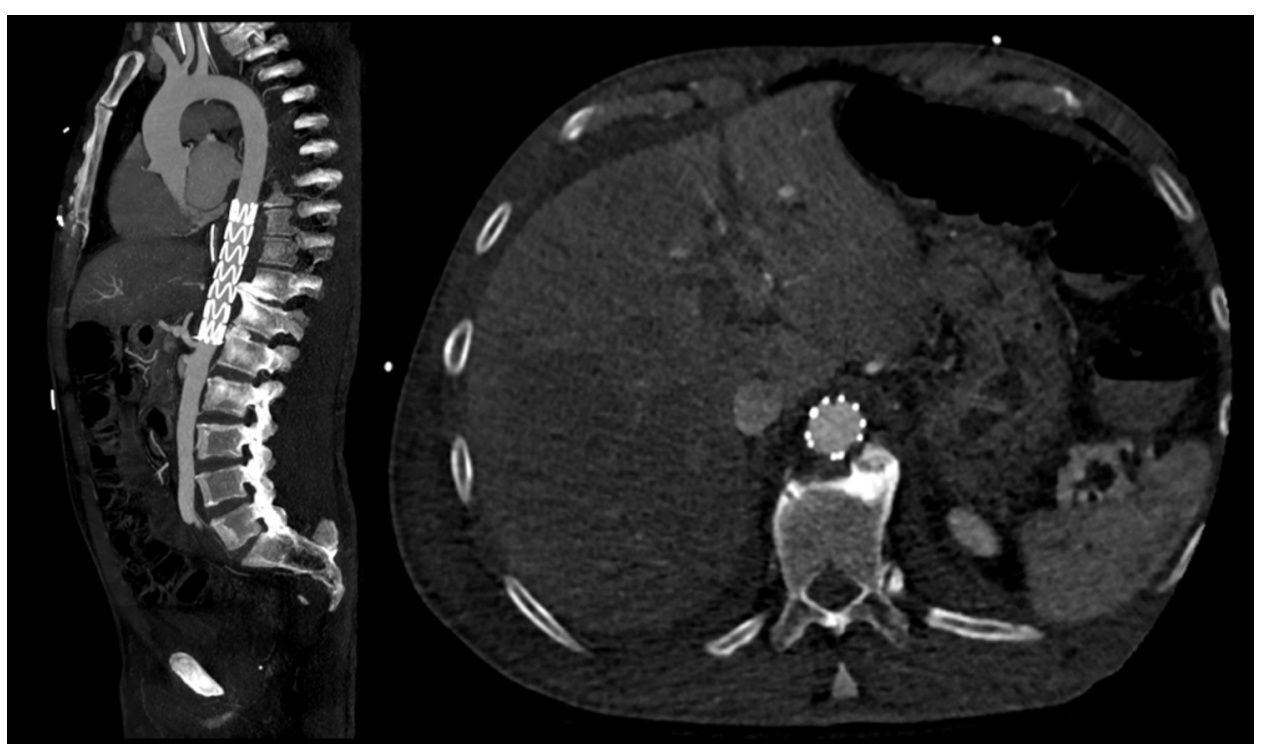

FIGURE 2. Computed tomographic angiography after stent-graft placement. The imaging confirmed complete exclusion of the pseudoaneurysm and regression of the posterior mediastinal hematoma.

Angiographic control confirmed good positioning of the endograft without any residual leak. The postoperative course was uncomplicated. Computed tomographic angiography confirmed pseudoaneurysm exclusion and regression of the posterior mediastinal hematoma (Figure 2). The patient has resumed usual activity at 6 months of follow-up.

Traumatic aortic rupture is predominantly reported at the aortic isthmus as a result of sudden deceleration. ${ }^{1}$ Early and late results of thoracic endovascular aortic repair for traumatic aortic rupture are excellent, even in this young, high-risk patient population. ${ }^{2,3}$ We illustrate a rare traumatic rupture of the distal aorta caused by pinching between a prominent anterior thoracic vertebral osteophyte and a heavy weight. Endovascular repair allowed us to stabilize the patient and treat associated multiple lesions, avoiding cardiopulmonary bypass and a high-risk open repair.

\section{References}

1. Asaid R, Boyce G, Atkinson N. Endovascular repair of acute traumatic aortic injury: experience of a level-1 trauma center. Ann Vasc Surg. 2014;28: 1391-5.

2. Khoynezhad A, Donayre CE, Azizzadeh A, White R, RESCUE investigators. One-year results of thoracic endovascular aortic repair for blunt thoracic aortic injury (RESCUE trial). J Thorac Cardiovasc Surg. 2015;149: 155-61.e4.

3. Canaud L, Marty-Ane C, Ziza V, Branchereau P, Alric P. Minimum 10-year follow-up of endovascular repair for acute traumatic transection of the thoracic aorta. J Thorac Cardiovasc Surg. 2015;149:825-9. 